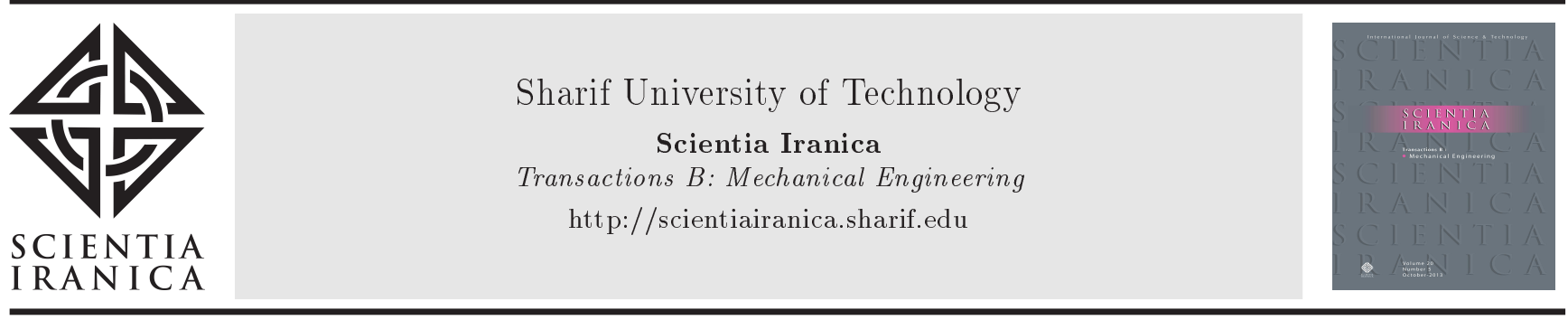

\title{
MHD forced convection flow and heat transfer of ferrofluids over a moving flat plate with uniform heat flux and second-order slip effects
}

\author{
N. Ramlia ${ }^{\mathrm{a}}$ S. Ahmad ${ }^{\mathrm{a}}$, and I. Pop ${ }^{\mathrm{b}, *}$ \\ a. School of Mathematical Sciences, Universiti Sains Malaysia, 11800 USM, Penang, Malaysia. \\ b. Faculty of Mathematics and Computer Science, Babes-Bolyai University, 400084 Cluj-Napoca, Romania.
}

Received 23 December 2016; received in revised form 10 March 2017; accepted 10 June 2017

\section{KEYWORDS \\ MHD; \\ Heat transfer; \\ Ferrofluids; \\ Heat flux; \\ Second-order slip.}

\begin{abstract}
In this study, the problem of a two-dimensional forced convection MHD flow and heat transfer of ferrofluids over a moving flat plate is investigated, considering the effects of uniform heat flux and second-order slip. By applying the similarity transformation, the governing equations are reconstructed into the similarity equations, and the resulting equations are solved via a shooting technique. Then, we implement a stability analysis in order to determine which solutions are stable and physically realizable. The effects of the magnetic parameter, moving parameter, mass transfer parameter, first-order surface slip parameter, second-order surface slip parameter and volume fraction of solid ferroparticles on the dimensionless velocity, temperature, skin friction, and Nusselt numbers are discussed in the form of tabular and graphical presentations. For the present study, we consider the results based on three preferred ferroparticles: magnetite, cobalt ferrite, and Mn-Zn ferrite in water- and kerosene-based fluids. The results display the existence of dual solutions for a plate moving towards the origin in which the first solution is stable and physically realizable, while the second solution is not. Moreover, it is demonstrated that the combined effects of the magnetic, moving, mass transfer, and slip parameters, together with the volume fraction of ferrofluids, delay the boundary layer separation.
\end{abstract}

(C) 2018 Sharif University of Technology. All rights reserved.

\section{Introduction}

First used by Choi [1], the nanofluids constitute heat transfer fluid containing suspensions of nanoparticles with the size ranging under $100 \mathrm{~nm}$. He studied the problem of nanofluids which helps exhibit the thermal properties of fluids with nanoparticles. The main purpose was to demonstrate theoretically the feasibility of the concept of nanofluids. Then, it was widely used

*. Corresponding author. Tel.: +040264405300;

Fax: +040264591905

E-mail address: popm.ioan@yahoo.co.uk (I. Pop)

doi: $10.24200 /$ sci.2017.4343 by other researchers such as Xuan and Li [2], Tiwari and Das [3], Ahmad et al. [4], and others.

On the other hand, we can notice that the number of researches on flow analysis of nanofluids with the interaction of magnetic field has increased enormously. Magnetic nanofluids, known as ferrofluids, consist of magnetic nanoparticles (3-15 nm) and carrier fluid. In order to maintain a constant suspension state, the ultrafine particles are covered by an appropriate surfactant, besides being considered as particles of a single magnetic domain. Moreover, by considering the effect of external magnetic fields, the ferrofluids can facilitate some particular achievements, e.g. helping control the properties of flow and physical properties of the ferrofluids. 
Tangthieng et al. [5] carried out a study to describe the enhancement of heat transfer in ferrofluids, which dealt with the steady magnetic fields. They developed the problem based on the flow between vertical parallel plates and in a box, concluding that the heat transfer significantly increases with the influence of magnetic field gradient. Besides, Kuncser et al. [6] and $\mathrm{Li}$ et al. [7] came up with the studies of the use of ferrofluids whose aim is to show the heat transfer enhancement in the boundary layer. Recently, Khan et al. [8] investigated the problem of flow and heat transfer of ferrofluids past a flat plate with uniform heat flux and slip velocity. The results revealed that the heat transfer rate increases, and the friction factor reduces with the increase in slip parameter.

Recently, many researchers have studied magnetohydrodynamics (MHD) due to its interesting applications in industry including polymer technology, geophysics, solar physics, and many more. MHD can be defined as the science of motion of electrically conducting fluids based on the influence of applied magnetic forces. Sheremet et al. [9] studied numerically the effect of magnetic field on the unsteady natural convection in a wavy-walled channel using the mathematical model proposed by Buongiorno. Bondareva et al. extended the problem to the unsteady natural convection in a right-angle trapezoidal cavity filled with a nanofluid [10]. Considering the results, they found that the key parameters exert significant effects on the flow, heat and mass transfer characteristics.

The present study investigates the problem of two-dimensional MHD flow and heat transfer of ferrofluids over a moving flat plate with the effects of uniform heat flux and second-order slip. The effects of moving, magnetic, mass transfer, and slip parameters together with volume fraction of solid ferroparticles on the dimensionless velocity, temperature, skin friction, and Nusselt number are developed for the preferred ferroparticles in water- and kerosene-based ferrofluids.

\section{Basic equations}

Consider the problem of forced convection boundary layer flow and heat transfer of preferred water- and kerosene-based ferrofluids over a moving horizontal permeable flat plate in a variable magnetic field $B(x)$. In this study, we assume the flow to be steady, laminar, two-dimensional, and incompressible; besides, the base fluids and preferred nanoparticles are in thermal equilibrium. In addition, the flow takes place in region $y>0$ and is driven by a moving surface with velocity $u_{w}=\lambda U_{\infty}+u_{\text {slip }}$, where $u_{\text {slip }}$ is the surface slip velocity and $\lambda$ is a dimensionless constant moving parameter with $\lambda>0$ for a surface moving out of the origin and $\lambda<0$ for a surface moving towards the origin, as shown in Figure 1. It is assumed that the uniform heat flux from the surface is $q_{w}$, while the temperature of the ambient fluid is $T_{\infty}$. Under these assumptions, the basic equations of the problem under consideration are as follows (see [8]):

$$
\begin{aligned}
& \frac{\partial u}{\partial x}+\frac{\partial v}{\partial y}=0 \\
& u \frac{\partial u}{\partial x}+v \frac{\partial u}{\partial y}=\nu_{n f} \frac{\partial^{2} u}{\partial y^{2}}-\frac{\sigma B^{2}(x)}{\rho_{n f}}\left(u-U_{\infty}\right), \\
& u \frac{\partial T}{\partial x}+v \frac{\partial T}{\partial y}=\alpha_{n f} \frac{\partial^{2} T}{\partial y^{2}}
\end{aligned}
$$

where $x$ and $y$ are the Cartesian coordinates measured perpendicular and normal to the plate, $u$ and $v$ are the velocity components along $x$ - and $y$-axes, $T$ is the temperature of the nanofluid, $\nu_{n f}$ is the kinematic viscosity of the nanofluid, $\alpha_{n f}$ is the thermal diffusivity of the nanofluid, and $\rho_{n f}$ is the density of the nanofluid, presented by Relations (4) in the paper by Khan et al. [8]:

$$
\begin{aligned}
& \nu_{n f}=\frac{\mu_{n f}}{\rho_{n f}}, \quad \mu_{n f}=\frac{\mu_{f}}{(1-\varphi)^{2.5}}, \\
& \alpha_{n f}=\frac{k_{n f}}{\left(\rho C_{p}\right)_{n f}}, \quad \rho_{n f}=(1-\varphi) \rho_{f}+\varphi \rho_{s}, \\
& \left(\rho C_{p}\right)_{n f}=(1-\varphi)\left(\rho C_{p}\right)_{f}+\varphi\left(\rho C_{p}\right)_{s}, \\
& \frac{k_{n f}}{k_{f}}=\frac{k_{s}+2 k_{f}-2 \varphi\left(k_{f}-k_{s}\right)}{k_{s}+2 k_{f}+\varphi\left(k_{f}-k_{s}\right)}
\end{aligned}
$$

where $k_{n f}$ is the thermal conductivity of the nanofluid, $\left(\rho C_{p}\right)_{n f}$ is the heat capacity of nanofluid, and $\varphi$ is the volume fraction of solid particle of the nanofluid.

Assuming that Eqs. (1)-(3) are subjected to the boundary conditions:

$$
\begin{aligned}
& u=\lambda U_{\infty}+\gamma \frac{\partial u}{\partial y}+\omega \frac{\partial^{2} u}{\partial y^{2}}, \quad v=v_{0}, \\
& -k_{n f} \frac{\partial T}{\partial y}=q_{w}, \quad \text { at } \quad y=0, \\
& u \rightarrow U_{\infty}, \quad T \rightarrow T_{\infty}, \quad \text { as } \quad y \rightarrow \infty
\end{aligned}
$$

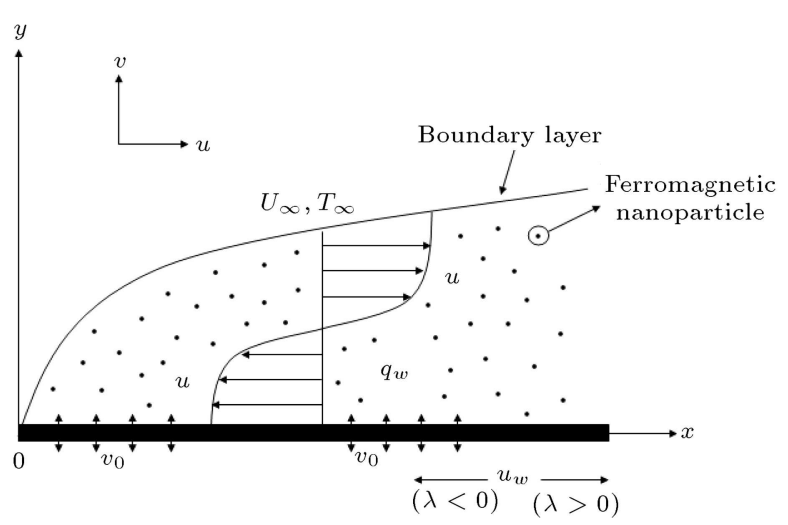

Figure 1. Physical model and coordinate system. 
where $\gamma$ is the first-order surface velocity slip, $\omega$ is the second-order surface velocity slip, and $U_{\infty}$ is the free stream velocity.

\section{Solution for the steady case}

It is assumed that $B(x)=B_{0} x^{-1 / 2}$, where $B_{0}$ is the strength of the applied magnetic field for the sake of Eqs. (1) to (3) having similarity solutions. Then, the similarity solution to Eqs. (1) to (4) is found through proposing the following transformation:

$$
\begin{aligned}
& \psi(x, y)=\nu_{f} \sqrt{\operatorname{Re}_{x}} f(\eta), \quad \theta(\eta)=\frac{T-T_{\infty}}{q_{w} x / k_{f}} \sqrt{\operatorname{Re}_{x}}, \\
& \eta=\frac{y}{x} \sqrt{\operatorname{Re}_{x}}
\end{aligned}
$$

where $\eta$ is the similarity variable and $\operatorname{Re}_{x}=U_{\infty} x / \nu_{f}$ is the local Reynolds number based on the free stream velocity, and $\nu_{f}$ is the kinematic viscosity of the base fluid. Furthermore, $\psi(x, y)$ is the streamline, represented in the common form of $u=\frac{\partial \psi}{\partial y}$ and $v=$ $-\frac{\partial \psi}{\partial x}$. Thus, we have:

$$
u=U_{\infty} f^{\prime}(\eta), \quad v=-\nu_{f} \frac{\sqrt{\operatorname{Re}_{x}}}{2 x}\left[f(\eta)-\eta f^{\prime}(\eta)\right]
$$

where prime denotes differentiation with respect to $\eta$. Then, note that:

$$
v_{w}(x)=-\nu_{f} \frac{\sqrt{\operatorname{Re}_{x}}}{2 x} f(0) .
$$

We now take:

$$
v_{w}(x)=-\nu_{f} \frac{\sqrt{\mathrm{Re}_{x}}}{2 x} S=v_{0}
$$

where $S=-2 v_{0} \sqrt{x L} / \nu_{f} \sqrt{\operatorname{Re}_{x}}=-2 v_{0} / \sqrt{U_{\infty} \nu_{f} / L}$ is the constant mass transfer parameter with $S>0$ for suction and $S<0$ for injection, and $L$ is the characteristic length of the sheet. Besides, we assume that $\gamma=\sqrt{x \nu_{f} / U_{\infty}} a$ and $\omega=\left(x \nu_{f} / U_{\infty}\right) b$ where $a(>0)$ and $b(<0)$ are the constant first- and secondorder surface slip parameters (see [11]).

Then, Eq. (6) is substituted into Eqs. (1)-(3); thus, the following ordinary differential equations are obtained:

$$
\begin{aligned}
& \frac{1}{(1-\varphi)^{2.5}\left(1-\varphi+\varphi \rho_{s} / \rho_{f}\right)} f^{\prime \prime \prime}+\frac{1}{2} f f^{\prime \prime} \\
& +\frac{M}{1-\varphi+\varphi \rho_{s} / \rho_{f}}\left(1-f^{\prime}\right)=0 \\
& \frac{k_{n f} / k_{f}}{1-\varphi+\varphi\left(\rho C_{p}\right)_{s} /\left(\rho C_{p}\right)_{f}} \frac{1}{\operatorname{Pr}} \theta^{\prime \prime}+\frac{1}{2}\left(f \theta^{\prime}-f^{\prime} \theta\right)=0
\end{aligned}
$$

subject to the boundary conditions:

$$
\begin{aligned}
& f(0)=S, \quad f^{\prime}(0)=\lambda+a f^{\prime \prime}(0)+b f^{\prime \prime \prime}(0), \\
& \theta^{\prime}(0)=-\frac{k_{f}}{k_{n f}} \quad f^{\prime}(\eta) \rightarrow 1, \quad \theta(\eta) \rightarrow 0 \\
& \text { as } \quad \eta \rightarrow \infty,
\end{aligned}
$$

where primes denote differentiation with respect to $\eta$, $\operatorname{Pr}=\left(\mu C_{p}\right)_{f} / k_{f}$ is the Prandtl number, and $M=$ $\sigma B_{0}^{2} / \rho_{f} U_{\infty}$ is the magnetic parameter.

Quantities of physical interest in this problem are skin friction coefficient, $C_{f}$, and local Nusselt number, $\mathrm{Nu}_{x}$, defined as follows:

$$
C_{f}=\frac{\tau_{w}}{\rho_{f} U_{\infty}^{2}}, \quad \mathrm{Nu}_{x}=\frac{x q_{w}}{k_{f}\left(T_{w}-T_{\infty}\right)},
$$

where $\tau_{w}$ is the shear stress along the plate, and:

$$
\tau_{w}=\mu_{n f}\left(\frac{\partial u}{\partial y}\right)_{y=0}, \quad q_{w}=-k_{n f}\left(\frac{\partial T}{\partial y}\right)_{y=0} .
$$

Using Eqs. (6), (13), and (15), we obtain:

$$
\operatorname{Re}_{x}^{1 / 2} C_{f}=\frac{f^{\prime \prime}(0)}{(1-\varphi)^{2.5}}, \quad \operatorname{Re}_{x}^{-1 / 2} \mathrm{Nu}_{x}=\frac{1}{\theta(0)}
$$

\section{Flow stability}

Weidman et al. [12] and Roşca and Pop [11] demonstrated that the lower branch solutions are unstable (not physically realizable), while the upper branch solutions are stable (physically realizable). These characteristics are assessed by investigating the unsteady form of Eqs. (10)-(12). Thus, new dimensionless time variable, $\tau=U_{\infty} t / x$, is proposed, and it is noted that the use of $\tau$ is related to an initial value problem. Thus, unsteady Eqs. (1) to (3) are as follows:

$$
\begin{aligned}
& \frac{\partial u}{\partial x}+\frac{\partial v}{\partial y}=0 \\
& \frac{\partial u}{\partial t}+u \frac{\partial u}{\partial x}+v \frac{\partial u}{\partial y}=\nu_{n f} \frac{\partial^{2} u}{\partial y^{2}}-\frac{\sigma B^{2}(x)}{\rho_{n f}}\left(u-U_{\infty}\right) \\
& \frac{\partial T}{\partial t}+u \frac{\partial T}{\partial x}+v \frac{\partial T}{\partial y}=\alpha_{n f} \frac{\partial^{2} T}{\partial y^{2}}
\end{aligned}
$$

where $t$ denotes the time. Now, we will introduce the following new variables:

$$
\begin{aligned}
& u=U_{\infty} \frac{\partial f}{\partial \eta}(\eta, \tau), \\
& v=-\frac{\nu_{f}}{2 x} \sqrt{\operatorname{Re}_{x}}\left[f(\eta, \tau)-\eta \frac{\partial f}{\partial \eta}(\eta, \tau)-2 \tau \frac{\partial f}{\partial \tau}\right], \\
& \theta(\eta, \tau)=\frac{T-T_{\infty}}{q_{w} x / k_{f}} \sqrt{\operatorname{Re}_{x}}, \quad \eta=\frac{y}{x} \sqrt{\operatorname{Re}_{x}} \\
& \tau=\frac{U_{\infty}}{x} t .
\end{aligned}
$$


Further, Eqs. (16)-(18) can be written as follows:

$$
\begin{aligned}
& \frac{1}{(1-\varphi)^{2.5}\left(1-\varphi+\varphi \rho_{s} / \rho_{f}\right)} \frac{\partial^{3} f}{\partial \eta^{3}}+\frac{1}{2} f \frac{\partial^{2} f}{\partial \eta^{2}} \\
& +\left(\tau \frac{\partial f}{\partial \eta}-1\right) \frac{\partial^{2} f}{\partial \eta \partial \tau}-\tau \frac{\partial f}{\partial \tau} \frac{\partial^{2} f}{\partial \eta^{2}} \\
& +\frac{M}{1-\varphi+\varphi \rho_{s} / \rho_{f}}\left(1-\frac{\partial f}{\partial \eta}\right)=0 \\
& \frac{k_{n f} / k_{f}}{1-\varphi+\varphi\left(\rho C_{p}\right)_{s} /\left(\rho C_{p}\right)_{f}} \frac{1}{\operatorname{Pr}} \frac{\partial^{2} \theta}{\partial \eta^{2}}+\frac{1}{2}\left(f \frac{\partial \theta}{\partial \eta}-\frac{\partial f}{\partial \eta} \theta\right) \\
& +\left(\tau \frac{\partial f}{\partial \eta}-1\right) \frac{\partial \theta}{\partial \tau}-\tau \frac{\partial f}{\partial \tau} \frac{\partial \theta}{\partial \eta}=0
\end{aligned}
$$

subject to the boundary conditions:

$$
\begin{aligned}
& f(0, \tau)=S, \\
& \frac{\partial f}{\partial \eta}(0, \tau)=\lambda+a \frac{\partial^{2} f}{\partial \eta^{2}}(0, \tau)+b \frac{\partial^{3} f}{\partial \eta^{3}}(0, \tau), \\
& \frac{\partial \theta}{\partial \eta}(0, \tau)=-\frac{k_{f}}{k_{n f}}, \quad \frac{\partial}{\partial \eta}(\eta, \tau) \rightarrow 1, \\
& \theta(\eta, \tau) \rightarrow 0 \quad \text { as } \quad \eta \rightarrow \infty .
\end{aligned}
$$

To examine the stability of the steady flow solution $f(\eta)=f_{0}(\eta)$ and $\theta(\eta)=\theta_{0}(\eta)$ to solve the boundaryvalue problem of Eqs. (7)-(9), the following are defined (see [12] or [11]):

$$
\begin{aligned}
& f(\eta, \tau)=f_{0}(\eta)+e^{-\zeta \tau} F(\eta, \tau), \\
& \theta(\eta, \tau)=\theta_{0}(\eta)+e^{-\zeta \tau} G(\eta, \tau),
\end{aligned}
$$

where $\zeta$ is an unknown eigenvalue parameter, and $F(\eta, \tau)$ and $G(\eta, \tau)$ are small relative to $f_{0}(\eta)$ and $\theta_{0}(\eta)$. We then substitute Eq. (23) into Eqs. (20) and $(21)$ to obtain the following linearized problem:

$$
\begin{aligned}
& \frac{1}{(1-\varphi)^{2.5}\left(1-\varphi+\varphi \rho_{s} / \rho_{f}\right)} \frac{\partial^{3} F}{\partial \eta^{3}}+\frac{1}{2} f_{0} \frac{\partial^{2} F}{\partial \eta^{2}} \\
& +\left(\zeta-\tau \zeta f_{0}^{\prime}-\frac{M}{1-\varphi+\varphi \rho_{s} / \rho_{f}}\right) \frac{\partial F}{\partial \eta} \\
& +\left(\frac{1}{2}+\tau \zeta\right) f_{0}^{\prime \prime} F-\tau f_{0}^{\prime \prime} \frac{\partial F}{\partial \tau}+\left(\tau f_{0}^{\prime}-1\right) \frac{\partial^{2} F}{\partial \eta \partial \tau}=0 \\
& \frac{k_{n f} / k_{f}}{1-\varphi+\varphi\left(\rho C_{p}\right)_{s} /\left(\rho C_{p}\right)_{f}} \frac{1}{\operatorname{Pr}} \frac{\partial^{2} G}{\partial \eta^{2}}+\frac{1}{2} f_{0} \frac{\partial G}{\partial \eta} \\
& -\left(\frac{1}{2} f_{0}^{\prime}+\tau \zeta f_{0}^{\prime}-\zeta\right) G+\left(\frac{1}{2}+\tau \zeta\right) F \theta_{0}^{\prime} \\
& -\frac{1}{2} \theta_{0} \frac{\partial F}{\partial \eta}+\left(\tau f_{0}^{\prime}-1\right) \frac{\partial G}{\partial \tau}-\tau \theta_{0}^{\prime} \frac{\partial F}{\partial \tau}=0,
\end{aligned}
$$

along with the boundary conditions:

$$
\begin{aligned}
& F(0, \tau)=0, \\
& \frac{\partial F}{\partial \eta}(0, \tau)=a \frac{\partial^{2} F}{\partial \eta^{2}}(0, \tau)+b \frac{\partial^{3} f}{\partial \eta^{3}}(0, \tau), \\
& \frac{\partial G}{\partial \eta}(0, \tau)=0, \quad \frac{\partial F}{\partial \eta}(\eta, \tau) \rightarrow 0, \\
& G(\eta, \tau) \rightarrow 0, \quad \text { as } \quad \eta \rightarrow \infty .
\end{aligned}
$$

As proposed by Weidman et al. [12], the stability of the steady flow and the result of heat transfers $f_{0}(\eta)$ and $\theta_{0}(\eta)$ are investigated by defining $\tau=0$; therefore, $F=F_{0}(\eta)$ and $G=G_{0}(\eta)$ in Eqs. (24) and (25) to distinguish the initial growth or decay of the solution to Eq. (23). To examine our numerical process, we have to solve the linear eigenvalue problem:

$$
\begin{aligned}
& \frac{1}{(1-\varphi)^{2.5}\left(1-\varphi+\varphi \rho_{s} / \rho_{f}\right)} F_{0}^{\prime \prime \prime}+\frac{1}{2} f_{0} F_{0}^{\prime \prime} \\
& +\left(\zeta-\frac{M}{1-\varphi+\varphi \rho_{s} / \rho_{f}}\right) F_{0}^{\prime}+\frac{1}{2} f_{0}^{\prime \prime} F_{0}=0 \\
& \frac{k_{n f} / k_{f}}{1-\varphi+\varphi\left(\rho C_{p}\right)_{s} /\left(\rho C_{p}\right)_{f}} \frac{1}{\operatorname{Pr}} G_{0}^{\prime \prime}+\frac{1}{2} f_{0} G_{0}^{\prime} \\
& -\left(\frac{1}{2} f_{0}^{\prime}-\zeta\right) G_{0}+\frac{1}{2} \theta_{0}^{\prime} F_{0}-\frac{1}{2} \theta_{0} F_{0}^{\prime}=0
\end{aligned}
$$

along with the boundary conditions:

$$
\begin{aligned}
& F_{0}(0)=0, \quad F_{0}^{\prime}(0)=a F_{0}^{\prime \prime}(0)+b F_{0}^{\prime \prime \prime}, \quad G_{0}^{\prime}(0)=0, \\
& F_{0}^{\prime}(\eta) \rightarrow 0, \quad G_{0}(\eta) \rightarrow 0, \quad \text { as } \quad \eta \rightarrow \infty .
\end{aligned}
$$

It should be mentioned that for specific values of $\operatorname{Pr}, \varphi$, $a, b$, and $M$, the stability of steady flow solutions $f_{0}(\eta)$ and $\theta_{0}(\eta)$ is determined by the smallest eigenvalue $\zeta$. Referring to Harris et al. [13], the range of possible eigenvalues is determined through relaxing a boundary condition on $F_{0}(\eta)$ and $G_{0}(\eta)$. For this study, the condition of $F_{0}^{\prime}(\eta) \rightarrow 0$ as $\eta \rightarrow \infty$ is relaxed, and for a fixed value of $\zeta$, the system of Eqs. (27) and (28) is solved along with new boundary condition $F_{0}^{\prime \prime}(0)=1$.

\section{Results and discussion}

Numerical solutions to the governing ordinary differential Eqs. (10) and (11) with the boundary conditions of Eq. (12) were achieved using a shooting technique, which is done with the aid of shootlib function in Maple software. In this method, the governing ordinary differential equations must be converted into an equivalent initial value problem. Then, a suitable finite 
value of boundary layer thickness $\eta \rightarrow \infty$, namely $\eta_{\infty}$ must be chosen; for this study, $\eta_{\infty}=12$ is used. By defining the appropriate initial guesses for the missing values of $f^{\prime \prime}(0)$ and $\theta(0)$, an iterative solver with the support of shootlib in Maple 16 is used to produce the solutions which satisfy the boundary conditions. This process is repeated until the correct results are obtained, restricted to be less than $10^{-6}$ of shooting error. In this study, the dual solutions and all profiles are obtained to satisfy boundary conditions (12), yet in different patterns.

The effects of magnetic parameter, $M$, moving parameter, $\lambda$, mass transfer parameter, $S$, first-order surface slip parameter, $a$, second-order surface slip parameter, $b$, and volume fraction of solid ferroparticles, $\varphi$ on dimensionless velocity, $f^{\prime}(\eta)$, temperature, $\theta(\eta)$, skin friction, $\operatorname{Re}_{x}^{1 / 2} C_{f}$, and Nusselt numbers, $\mathrm{Re}_{x}^{-1 / 2} \mathrm{Nu}_{x}$, are examined for the three preferred ferroparticles, namely magnetite, cobalt ferrite, and MnZn ferrite in water- and kerosene-based ferrofluids. In the present study, two different Prandtl numbers are used, such that $\operatorname{Pr}=6.2$ for water-based ferrofluid and $\operatorname{Pr}=21$ for kerosene-based ferrofluid. In addition, the volume fraction of solid ferroparticles $\varphi$ is considered in the range of $0 \leq \varphi \leq 0.1$, where $\varphi=0$ represents the pure water or kerosene fluid.

Data related to the thermophysical properties of the base fluids (water and kerosene) and the ferroparticles (magnetite $\mathrm{Fe}_{3} \mathrm{O}_{4}$, cobalt ferrite $\mathrm{CoFe}_{2} \mathrm{O}_{4}$, and $\mathrm{Mn}-\mathrm{Zn}$ ferrite $\mathrm{Mn}-\mathrm{ZnFe}_{2} \mathrm{O}_{4}$ ) are used following Khan et al. [8], as listed in Table 1. In order to prove the accuracy of the present results, the values of the skin friction coefficient are compared with those reported by Cortell [14], Yazdi et al. [15], and Khan et al. [8], as shown in Table 2. The present results are found in good agreement with the published data, thus giving us some confidence in the present numerical results.

The variations of skin friction, $\operatorname{Re}_{x}^{1 / 2} C_{f}$, and Nusselt number, $\operatorname{Re}_{x}^{-1 / 2} \mathrm{Nu}_{x}$, with moving parameter, $\lambda$, and mass transfer parameter, $S$, are illustrated in Figures 2 to 13 for various values of $M, S, a, b$, and $\varphi$. From these figures, we notice that dual solutions exist for certain selected parameters. Note that the solid lines represent the first solution, while the dash lines represent the second solution. Both solutions are combined at critical point $\lambda_{c}$ or $S_{c}$, and it seems that

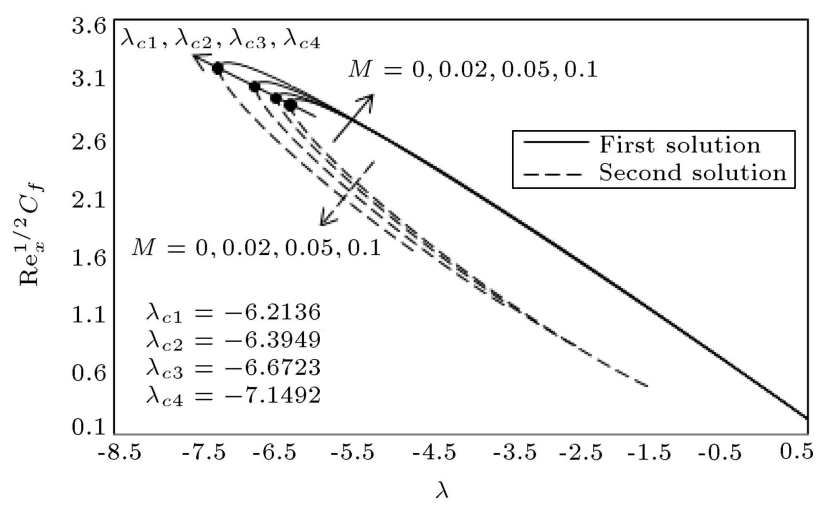

Figure 2. Variation of $\operatorname{Re}_{x}^{1 / 2} C_{f}$ with $\lambda$ for $\mathrm{Fe}_{3} \mathrm{O}_{4}$, water-based ferrofluids, $\operatorname{Pr}=6.2, S=2, a=1, b=-1$, $\varphi=0.1$, and with varying $M$.

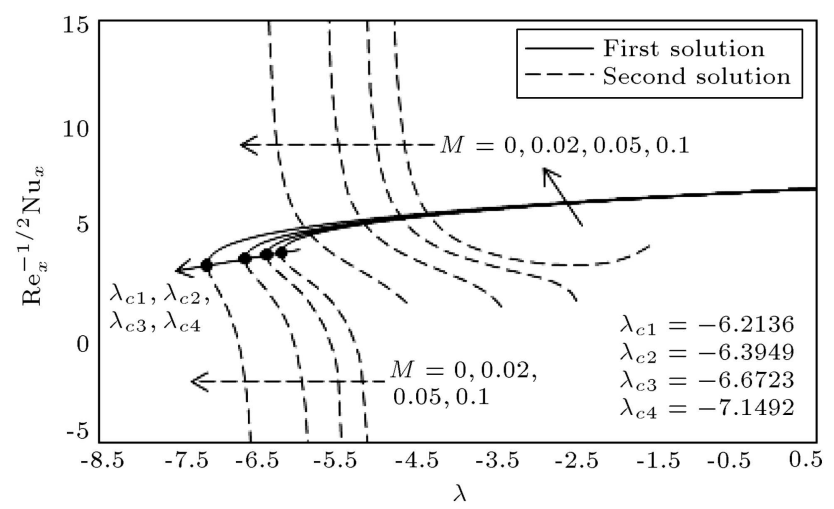

Figure 3. Variation of $\mathrm{Re}_{x}^{-1 / 2} \mathrm{Nu}_{x}$ with $\lambda$ for $\mathrm{Fe}_{3} \mathrm{O}_{4}$, water-based ferrofluids, $\operatorname{Pr}=6.2, S=2, a=1, b=-1$, $\varphi=0.1$, and with varying $M$.

Table 1. Thermophysical properties of base fluids and magnetic nanoparticles [8].

\begin{tabular}{|c|c|c|c|c|c|}
\hline \multirow{2}{*}{$\begin{array}{c}\text { Physical } \\
\text { properties }\end{array}$} & \multicolumn{2}{|c|}{ Base fluids } & \multicolumn{3}{|c|}{ Magnetic nanoparticles } \\
\hline & Water & Kerosene & $\mathrm{Fe}_{3} \mathrm{O}_{4}$ & $\mathrm{CoFe}_{2} \mathrm{O}_{4}$ & $\mathrm{Mn}-\mathrm{ZnFe}_{2} \mathrm{O}_{4}$ \\
\hline$\rho\left(\mathrm{Kg} / \mathrm{m}^{3}\right)$ & 997 & 783 & 5180 & 4907 & 4900 \\
\hline$C_{p}(\mathrm{~J} / \mathrm{Kg} . \mathrm{k})$ & 4179 & 2090 & 670 & 700 & 800 \\
\hline$k(\mathrm{~W} / \mathrm{m} . \mathrm{k})$ & 0.613 & 0.15 & 9.7 & 3.7 & 5 \\
\hline
\end{tabular}

Table 2. Comparison of $f^{\prime \prime}(0)$ for $a=0,0.5, b=0$, and $M=0,1$ when $\lambda=0, S=0$, and $\varphi=0$.

\begin{tabular}{ccccccc}
\hline $\boldsymbol{a}$ & $\boldsymbol{b}$ & $\boldsymbol{M}$ & Cortell [14] & Yazdi et al. [15] & Khan et al. [8] & Present study \\
\hline \multirow{2}{*}{0} & \multirow{2}{*}{0} & 0 & 0.33206 & - & 0.33206 & 0.33206 \\
\multirow{2}{*}{0.5} & 0 & 0 & - & 1.0440 & 1.04400 & 1.04400 \\
\hline
\end{tabular}




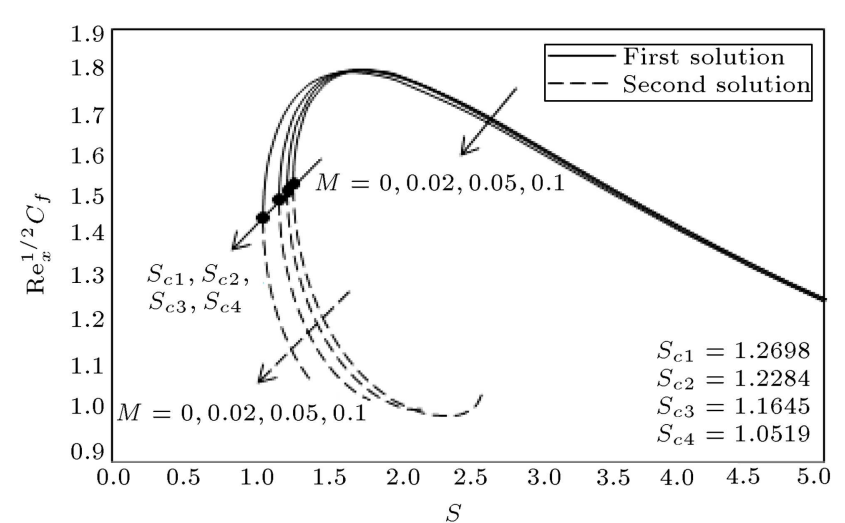

Figure 4. Variation of $\operatorname{Re}_{x}^{1 / 2} C_{f}$ with $S$ for $\mathrm{Fe}_{3} \mathrm{O}_{4}$, water-based ferrofluids, $\operatorname{Pr}=6.2, \lambda=-3, a=1, b=-1$, $\varphi=0.1$, and with varying $M$.

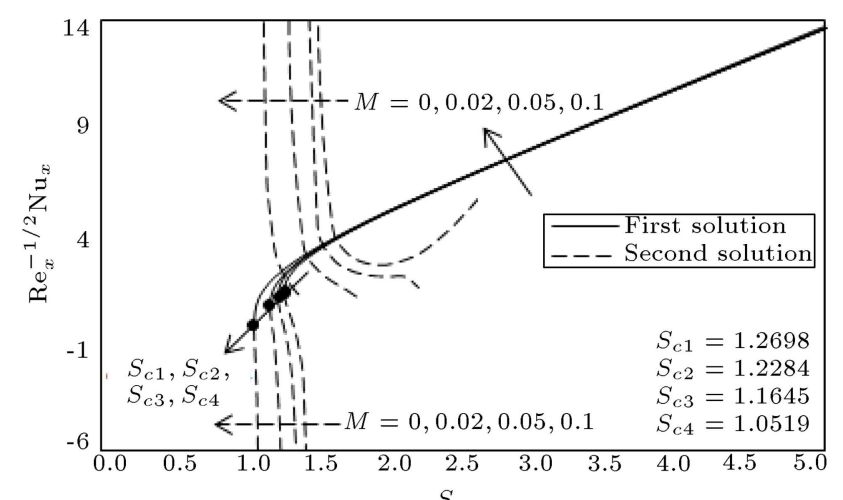

Figure 5. Variation of $\mathrm{Re}_{x}^{-1 / 2} \mathrm{Nu}_{x}$ with $S$ for $\mathrm{Fe}_{3} \mathrm{O}_{4}$, water-based ferrofluids, $\operatorname{Pr}=6.2, \lambda=-3, a=1, b=-1$, $\varphi=0.1$, and with varying $M$.

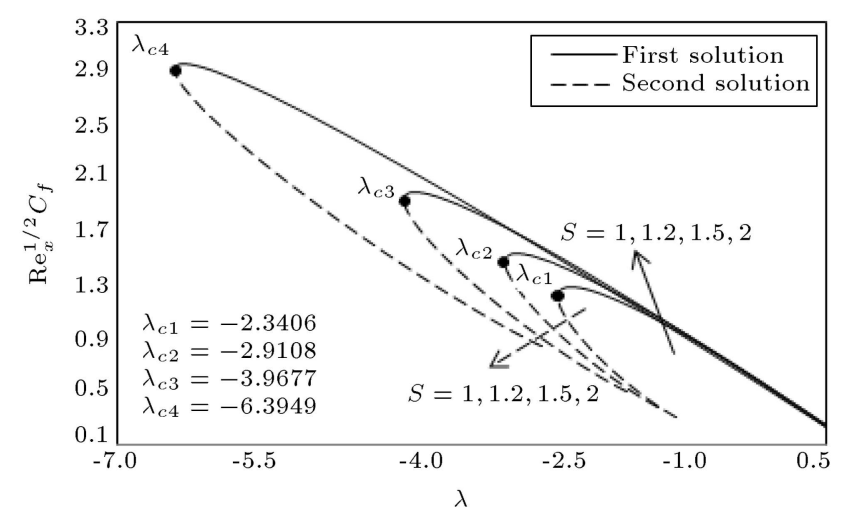

Figure 6. Variation of $\mathrm{Re}_{x}^{1 / 2} C_{f}$ with $\lambda$ for $\mathrm{Fe}_{3} \mathrm{O}_{4}$, water-based ferrofluids, $\operatorname{Pr}=6.2, M=0.02, a=1$, $b=-1, \varphi=0.1$, and with varying $S$.

there is no solution when $\lambda<\lambda_{c}$ or $S<S_{c}$. The results also indicate that critical values $\left|\lambda_{c}\right|$ and $\left|S_{c}\right|$ increase as the parameters of $M, a, b$, and $\varphi$ increase. Thus, these processes delay the boundary layer separation.

Further, a stability analysis is performed in order to get the smallest eigenvalues $\zeta$ in Eq. (23), with the main objective of testing the stability between those

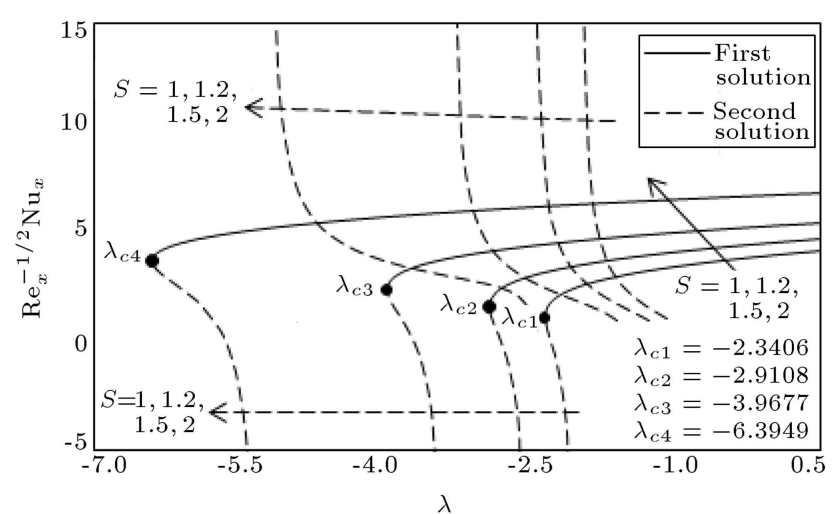

Figure 7. Variation of $\mathrm{Re}_{x}^{-1 / 2} \mathrm{Nu}_{x}$ with $\lambda$ for $\mathrm{Fe}_{3} \mathrm{O}_{4}$, water-based ferrofluids, $\operatorname{Pr}=6.2, M=0.02, a=1$, $b=-1, \varphi=0.1$, and with varying $S$.

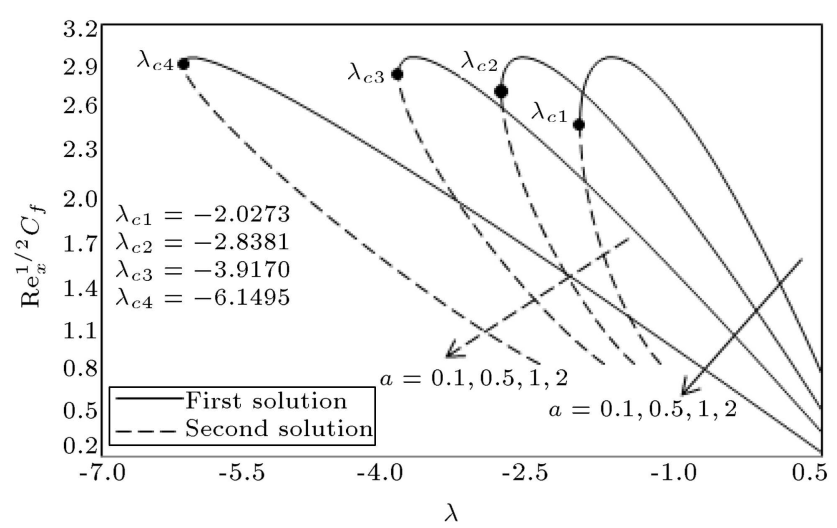

Figure 8. Variation of $\operatorname{Re}_{x}^{1 / 2} C_{f}$ with $\lambda$ for $\mathrm{Fe}_{3} \mathrm{O}_{4}$, water-based ferrofluids, $\operatorname{Pr}=6.2, M=0.02, S=2, b=0$, $\varphi=0.1$, and with varying $a$.

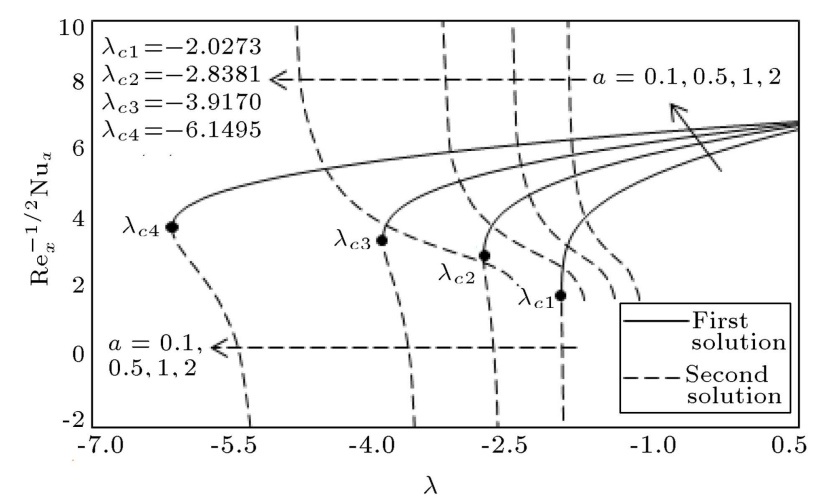

Figure 9. Variation of $\mathrm{Re}_{x}^{-1 / 2} \mathrm{Nu}_{x}$ with $\lambda$ for $\mathrm{Fe}_{3} \mathrm{O}_{4}$, water-based ferrofluids, $\operatorname{Pr}=6.2, M=0.02, S=2, b=0$, $\varphi=0.1$, and with varying $a$.

two solutions. It should be noted that the flow is stable when the smallest eigenvalue is positive, i.e. there is an initial decay. Nevertheless, the flow is unstable when the smallest eigenvalue is negative, i.e., there is an initial growth of disturbances. Table 3 shows the smallest eigenvalues $\zeta$ for $\mathrm{Fe}_{3} \mathrm{O}_{4}$ ferroparticle at several values of $\lambda(\lambda<0$, a plate moving towards the 


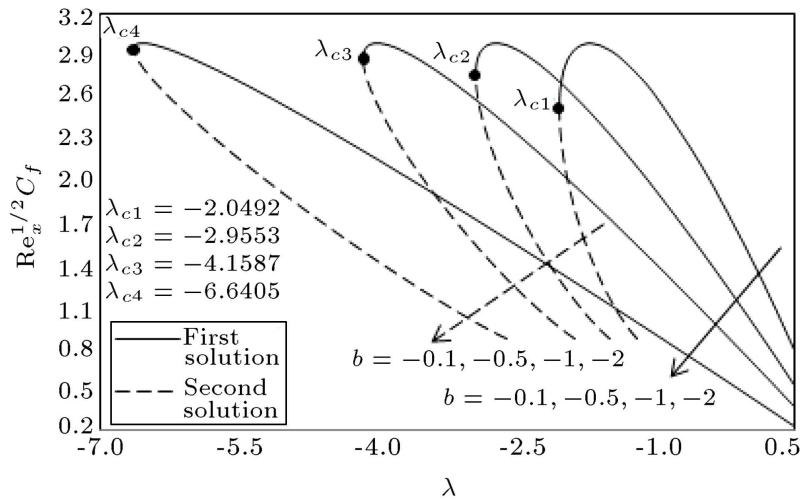

Figure 10. Variation of $\operatorname{Re}_{x}^{1 / 2} C_{f}$ with $\lambda$ for $\mathrm{Fe}_{3} \mathrm{O}_{4}$, water-based ferrofluids, $\operatorname{Pr}=6.2, M=0.02, S=2, a=0$, $\varphi=0.1$, and with varying $b$.

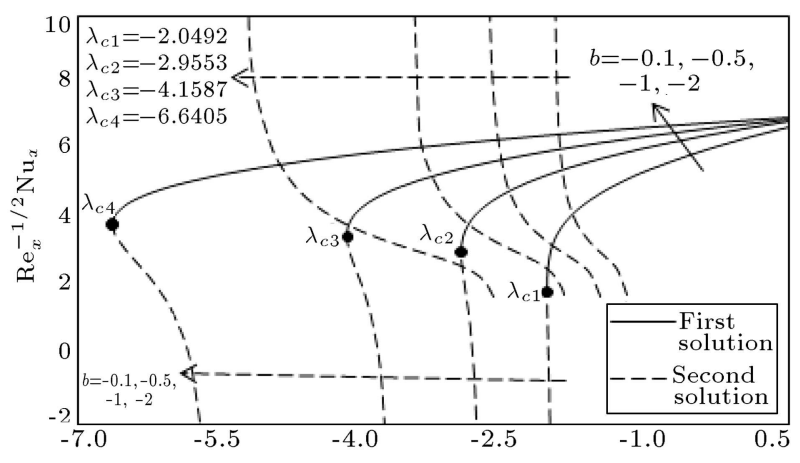

Figure 11. Variation of $\mathrm{Re}_{x}^{-1 / 2} \mathrm{Nu}_{x}$ with $\lambda$ for $\mathrm{Fe}_{3} \mathrm{O}_{4}$, water-based ferrofluids, $\operatorname{Pr}=6.2, M=0.02, S=2, a=0$, $\varphi=0.1$, and with varying $b$.

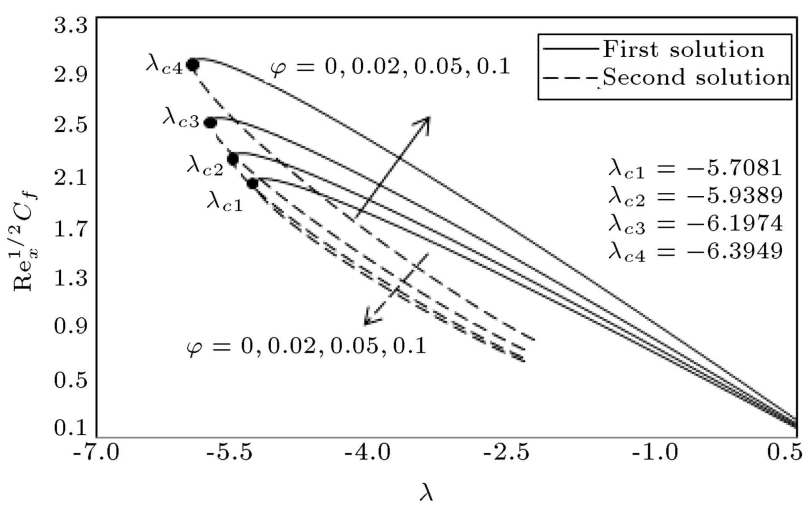

Figure 12. Variation of $\operatorname{Re}_{x}^{1 / 2} C_{f}$ with $\lambda$ for $\mathrm{Fe}_{3} \mathrm{O}_{4}$, water-based ferrofluids, $\operatorname{Pr}=6.2, M=0.02, S=2, a=1$, $b=-1$, and with varying $\varphi$.

origin), with various values $M$, when $S=2, a=1$, $b=-1, \varphi=0.1$, and $\operatorname{Pr}=6.2$ for water-based ferrofluid. It is shown from the stability analysis that $\zeta$ is positive for the first solution and negative for the second solution. From Eq. (23), it is inferred that the results will converge to steady flow solution when $\zeta$ is positive. Thus, we can conclude that the first solution

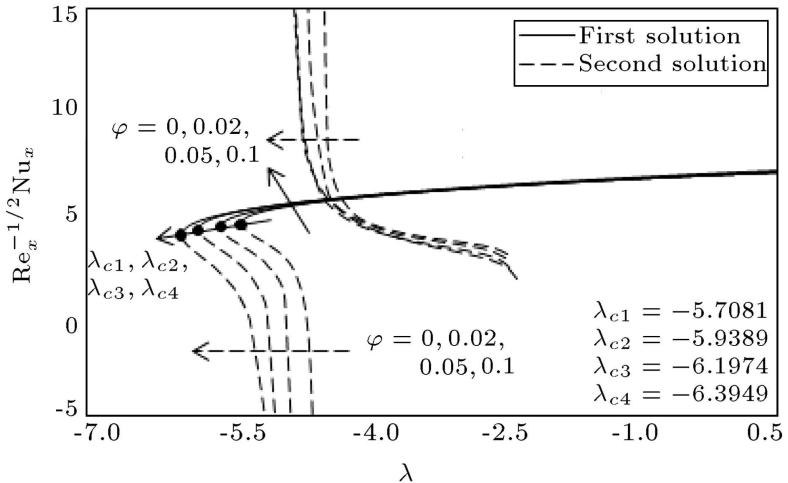

Figure 13. Variation of $\mathrm{Re}_{x}^{-1 / 2} \mathrm{Nu}_{x}$ with $\lambda$ for $\mathrm{Fe}_{3} \mathrm{O}_{4}$, water-based ferrofluids, $\operatorname{Pr}=6.2, M=0.02, S=2, a=1$, $b=-1$, and with varying $\varphi$.

Table 3. The smallest eigenvalues $\zeta$ for $\mathrm{Fe}_{3} \mathrm{O}_{4}$ ferroparticle at several values of $\lambda(\lambda<0$, a plate moving towards the origin), with various values of $M$, when $S=2$, $a=1, b=-1, \varphi=0.1$, and $\operatorname{Pr}=6.2$ (water-based ferrofluids).

\begin{tabular}{cccc}
\hline \multirow{2}{*}{$\boldsymbol{M}$} & $\boldsymbol{\lambda}$ & \multicolumn{2}{c}{$\boldsymbol{\zeta}$} \\
\cline { 3 - 4 } & & First solution & Second solution \\
\hline & -6.00 & 0.1733 & -0.1453 \\
& -6.10 & 0.1240 & -0.1092 \\
& -6.20 & 0.0414 & -0.0396 \\
& -6.21 & 0.0210 & -0.0206 \\
& & & \\
0.02 & -6.10 & 0.2048 & -0.1653 \\
& -6.20 & 0.1640 & -0.1381 \\
& -6.30 & 0.1121 & -0.0995 \\
& -6.39 & 0.0245 & -0.0239 \\
& & & \\
0.05 & -6.40 & 0.1943 & -0.1569 \\
& -6.50 & 0.1520 & -0.1285 \\
& -6.60 & 0.0962 & -0.0863 \\
& -6.67 & 0.0164 & -0.0161 \\
& & & -0.1460 \\
& -6.90 & 0.1820 & -0.1168 \\
& -7.00 & 0.1383 & -0.0701 \\
& -7.10 & 0.0771 & -0.0312 \\
\hline & -7.14 & 0.0325 & \\
\hline
\end{tabular}

is stable and physically realizable, while the second solution is unstable and not physically realizable.

In addition, it can be seen that Eqs. (10) and (11) with boundary conditions (12) give singularities $\lambda_{s i} / S_{s i}$ at some values of $\lambda=\lambda_{s i}(<0) / S=S_{s i}(>0)$, as illustrated in Table 4 . The singularity is based on the case that the flat plate is moving to a different direction of the free stream.

Tables 5 and 6 show the variations of skin friction, 
Table 4. Singularities $\lambda_{s i} / S_{s i}$ for different figures and parameters.

\begin{tabular}{|c|c|c|}
\hline Figure & Parameter & $\begin{array}{l}\text { Singularity } \\
\left(\lambda_{s i} / S_{s i}\right)\end{array}$ \\
\hline \multirow{4}{*}{3} & $M=0$ & $-4.93<\lambda_{s i}<-4.92$ \\
\hline & $M=0.02$ & $-5.26<\lambda_{s i}<-5.25$ \\
\hline & $M=0.05$ & $-5.73<\lambda_{s i}<-5.72$ \\
\hline & $M=0.1$ & $-6.48<\lambda_{s i}<-6.47$ \\
\hline \multirow{4}{*}{5} & $M=0$ & $1.47<S_{s i}<1.46$ \\
\hline & $M=0.02$ & $1.39<S_{s i}<1.38$ \\
\hline & $M=0.05$ & $1.28<S_{s i}<1.27$ \\
\hline & $M=0$ & $1.11<S_{s i}<1.1$ \\
\hline \multirow{4}{*}{7} & $S=1$ & $-2<\lambda_{s i}<-1.99$ \\
\hline & $S=1.2$ & $-2.48<\lambda_{s i}<-2.47$ \\
\hline & $S=1.5$ & $-3.35<\lambda_{s i}<-3.34$ \\
\hline & $S=2$ & $-5.26<\lambda_{s i}<-5.25$ \\
\hline \multirow{4}{*}{9} & $a=0.1$ & $-1.98<\lambda_{s i}<-1.97$ \\
\hline & $a=0.5$ & $-2.63<\lambda_{s i}<-2.62$ \\
\hline & $a=1$ & $-3.44<\lambda_{s i}<-3.43$ \\
\hline & $a=2$ & $-5.07<\lambda_{s i}<-5.06$ \\
\hline \multirow{4}{*}{11} & $b=-0.1$ & $-2<\lambda_{s i}<-1.99$ \\
\hline & $b=-0.5$ & $-2.72<\lambda_{s i}<-2.71$ \\
\hline & $b=-1$ & $-3.63<\lambda_{s i}<-3.62$ \\
\hline & $b=-2$ & $-5.45<\lambda_{s i}<-5.44$ \\
\hline \multirow{4}{*}{13} & $\varphi=0$ & $-4.82<\lambda_{s i}<-4.81$ \\
\hline & $\varphi=0.02$ & $-4.98<\lambda_{s i}<-4.97$ \\
\hline & $\varphi=0.05$ & $-5.16<\lambda_{s i}<-5.15$ \\
\hline & $\varphi=0.1$ & $-5.26<\lambda_{s i}<-5.25$ \\
\hline
\end{tabular}

$\operatorname{Re}_{x}^{1 / 2} C_{f}$, and Nusselt number, $\operatorname{Re}_{x}^{-1 / 2} \mathrm{Nu}_{x}$, with magnetic parameter, $M$, for each mixture of water- and kerosene-based ferrofluids, when $\lambda=-6, \varphi=0.1$, $S=2, a=1$, and $b=-1$. From these tables, we can conclude that the kerosene-based ferrofluids have higher skin friction and Nusselt number than the waterbased ferrofluids do.

Finally, Figures 14-19 present the dimensionless velocity and temperature profiles of $f^{\prime}(\eta)$ and $\theta(\eta)$ for different values of $\lambda$ and $M$ when $\mathrm{Fe}_{3} \mathrm{O}_{4}$ is applied to both water- and kerosene-based ferrofluids. From these figures, it is clearly observed that the boundary layer thickness for the first solution is thinner than that for the second solution. It is also seen that there exist two different temperature profiles, i.e.,

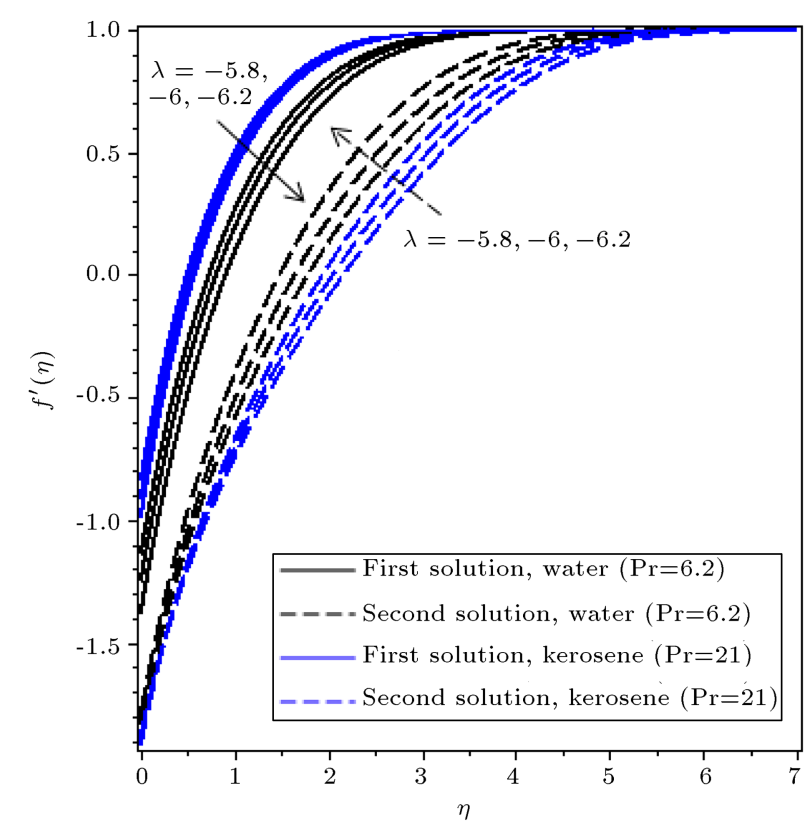

Figure 14. Dimensionless velocity profiles, $f^{\prime}(\eta)$, for several values of $\lambda \mathrm{Fe}_{3} \mathrm{O}_{4}$, when $\operatorname{Pr}=6.2, \varphi=0.1, a=1$, $b=-1, M=0.02, S=2$, and different based ferrofluids.

Table 5. Variation of $\operatorname{Re}_{x}^{1 / 2} C_{f}$ with $M$ for different ferroparticles with water- and kerosene-based ferrofluids when $\lambda=-6$, $\varphi=0.1, S=2, a=1$, and $b=-1$.

\begin{tabular}{|c|c|c|c|c|c|}
\hline \multirow{2}{*}{$\begin{array}{c}\text { Magnetic } \\
\text { nanoparticles }\end{array}$} & \multirow{2}{*}{$M$} & \multicolumn{2}{|c|}{ Water-based ferrofluids } & \multicolumn{2}{|c|}{ Kerosene-based ferrofluids } \\
\hline & & First solution & Second solution & First solution & Second solution \\
\hline \multirow{3}{*}{$\mathrm{Fe}_{3} \mathrm{O}_{4}$} & 0 & 2.9084 & 2.6413 & 2.9901 & 2.4374 \\
\hline & 0.02 & 2.9338 & 2.5698 & 2.9912 & 2.3963 \\
\hline & 0.05 & 2.9558 & 2.4797 & 2.9913 & 2.3374 \\
\hline \multirow{3}{*}{$\mathrm{CoFe}_{2} \mathrm{O}_{4}$} & 0 & 2.8429 & 2.7298 & 2.9827 & 2.4752 \\
\hline & 0.02 & 2.9012 & 2.6240 & 2.9861 & 2.4303 \\
\hline & 0.05 & 2.9371 & 2.5181 & 2.9889 & 2.3667 \\
\hline \multirow{3}{*}{$\mathrm{Mn}-\mathrm{ZnFe}{ }_{2} \mathrm{O}_{4}$} & 0 & 2.8396 & 2.7337 & 2.9825 & 2.4762 \\
\hline & 0.02 & 2.9001 & 2.6256 & 2.9859 & 2.4312 \\
\hline & 0.05 & 2.9366 & 2.5191 & 2.9888 & 2.3674 \\
\hline
\end{tabular}


Table 6. Variation of $\mathrm{Re}_{x}^{-1 / 2} \mathrm{Nu}_{x}$ with $M$ for different ferroparticles with water- and kerosene-based ferrofluids when $\lambda=-6, \varphi=0.1, S=2, a=1$, and $b=-1$.

\begin{tabular}{|c|c|c|c|c|c|}
\hline \multirow{2}{*}{$\begin{array}{c}\text { Magnetic } \\
\text { nanoparticles }\end{array}$} & \multirow{2}{*}{$M$} & \multicolumn{2}{|c|}{ Water-based ferrofluids } & \multicolumn{2}{|c|}{ Kerosene-based ferrofluids } \\
\hline & & First solution & Second solution & First solution & Second solution \\
\hline \multirow{3}{*}{$\mathrm{Fe}_{3} \mathrm{O}_{4}$} & 0 & 4.6705 & 3.0731 & 22.2051 & 20.5137 \\
\hline & 0.02 & 4.8251 & 2.2599 & 22.2520 & 20.4504 \\
\hline & 0.05 & 4.9818 & -1.1295 & 22.3154 & 20.3231 \\
\hline \multirow{3}{*}{$\mathrm{CoFe}_{2} \mathrm{O}_{4}$} & 0 & 4.3708 & 3.7791 & 22.0686 & 20.5630 \\
\hline & 0.02 & 4.6710 & 3.0214 & 22.1227 & 20.4917 \\
\hline & 0.05 & 4.8808 & 1.1299 & 22.1944 & 20.3916 \\
\hline \multirow{3}{*}{$\mathrm{Mn}-\mathrm{ZnFe}{ }_{2} \mathrm{O}_{4}$} & 0 & 4.3923 & 3.8253 & 22.6766 & 21.1743 \\
\hline & 0.02 & 4.7104 & 3.0392 & 22.7312 & 21.1036 \\
\hline & 0.05 & 4.9271 & 1.1137 & 22.8037 & 21.0060 \\
\hline
\end{tabular}

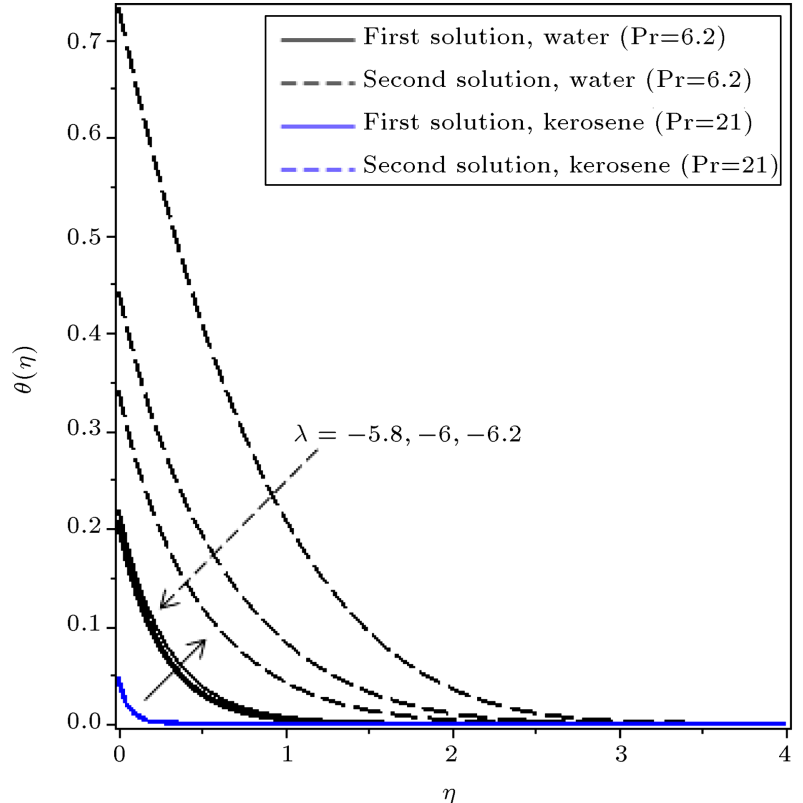

Figure 15. Dimensionless temperature profiles $\theta(\eta)$ for several values of $\lambda, \mathrm{Fe}_{3} \mathrm{O}_{4}$, when $\mathrm{Pr}=6.2, \varphi=0.1, a=1$, $b=-1, M=0.02, S=2$, and different based ferrofluids.

before and after singularities, when we are using two different values of $\lambda$. It is based on the existence of singularities. The velocity and thermal boundary-layer thicknesses increase in the first solution, while they decrease with the increase of $\lambda$ in the second solution. Other than that, it is observed that the velocity and thermal boundary layer thicknesses decrease in the first solution, while they increase with the increase of $M$ in the second solution. Further, we note that the velocity and thermal boundary-layer thicknesses are smaller for each of kerosene-based ferrofluids due to higher Prandtl number of kerosene; besides, far field

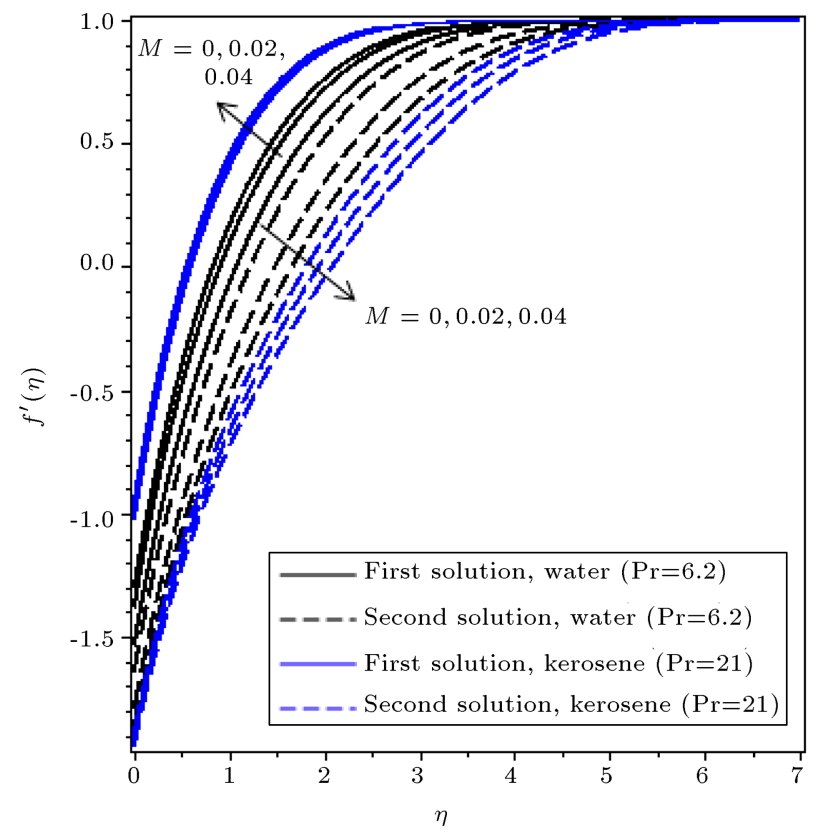

Figure 16. Dimensionless velocity profiles $f^{\prime}(\eta)$ for several values of $M, \mathrm{Fe}_{3} \mathrm{O}_{4}$, when $\mathrm{Pr}=6.2, \varphi=0.1, a=1$, $b=-1, S=2, \lambda=-6.2$, and different based ferrofluids.

boundary condition (12) is satisfied asymptotically, thus supporting the validity of the present numerical results.

\section{Conclusion}

The problem of the two-dimensional MHD flow and heat transfer over a moving flat plate was implemented for the effects of uniform heat flux and second-order slip. Numerical solutions to the ordinary differential equations were achieved using a shooting technique, done with the aid of shootlib function in Maple software 


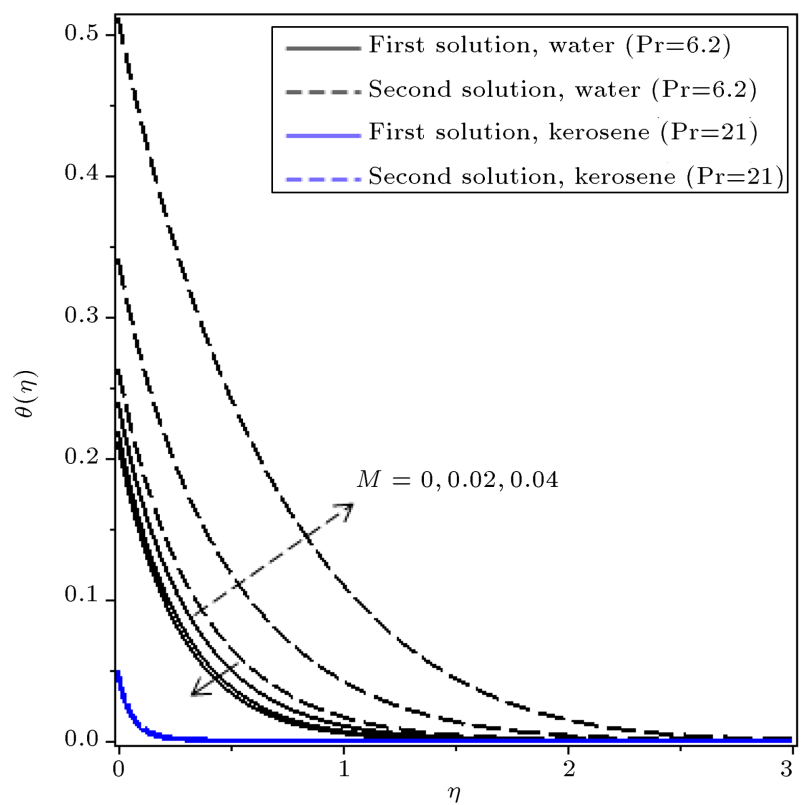

Figure 17. Dimensionless temperature profiles $\theta(\eta)$ for several values of $M, \mathrm{Fe}_{3} \mathrm{O}_{4}$, when $\mathrm{Pr}=6.2, \varphi=0.1, a=1$, $b=-1, S=2, \lambda=-6.2$, and different based ferrofluids.

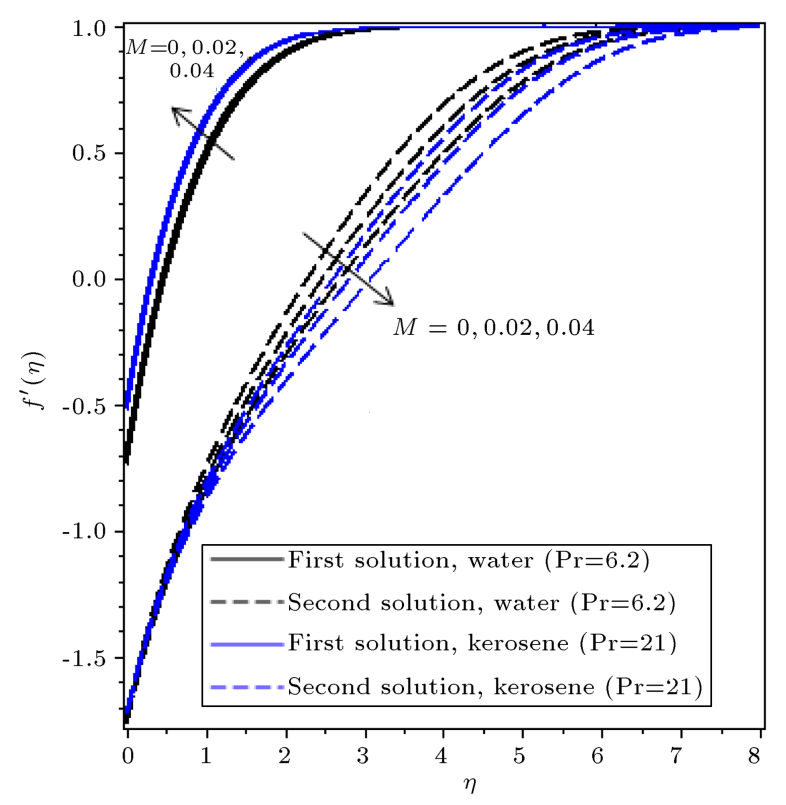

Figure 18. Dimensionless velocity profiles $f^{\prime}(\eta)$ for several values of $M, \mathrm{Fe}_{3} \mathrm{O}_{4}$, when $\mathrm{Pr}=6.2, \varphi=0.1, a=1$, $b=-1, S=2, \lambda=-4.8$, and different based ferrofluids.

for different values of governing parameters. The stability of solutions was obtained using function bvp 4c from Matlab. The effects of magnetic parameter, $M$, moving parameter, $\lambda$, mass transfer parameter, $S$, firstorder slip parameter, $a$, second-order slip parameter, $b$, and volume fraction of solid ferroparticles, $\varphi$, on flow characteristics were examined for the three preferred ferroparticles, namely magnetite, cobalt ferrite, and $\mathrm{Mn}-\mathrm{Zn}$ ferrite with water- and kerosene-based ferroflu-

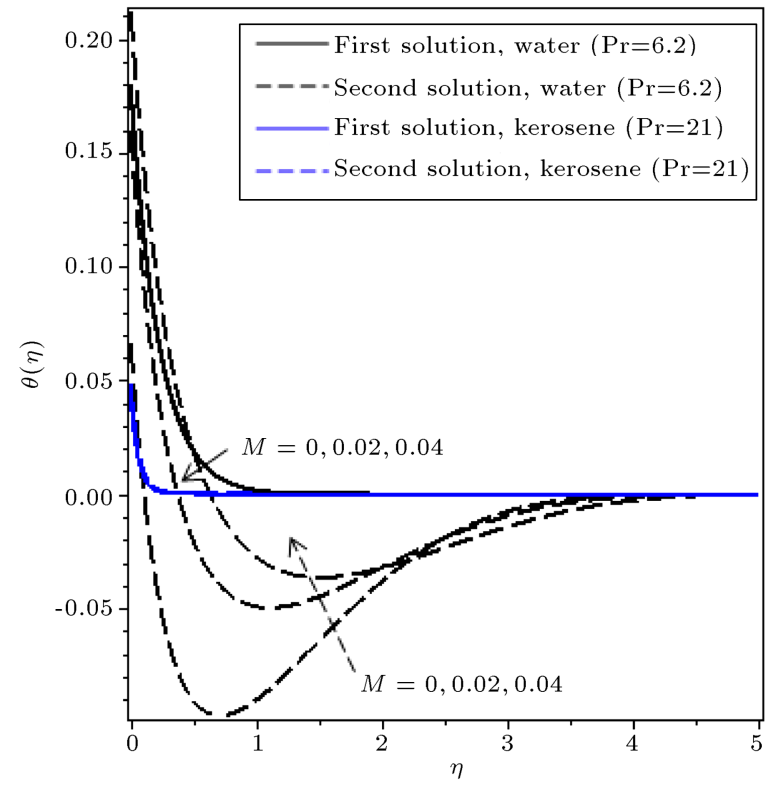

Figure 19. Dimensionless temperature profiles $\theta(\eta)$ for several values of $M, \mathrm{Fe}_{3} \mathrm{O}_{4}$, when $\mathrm{Pr}=6.2, \varphi=0.1, a=1$, $b=-1, S=2, \lambda=-4.8$, and different based ferrofluids.

ids. The numerical results were compared with the results of the previous work, suggesting good agreement between these results. Dual solutions exist within a certain range of $\lambda(\lambda<0)$, and unique solution exists when $\lambda>0$. The results indicate that critical values $\left|\lambda_{c}\right|$ and $\left|S_{c}\right|$ increase as the parameters of $M, a, b$, and $\varphi$ increase. Thus, these processes delay the boundary layer separation. Furthermore, it was observed that the boundary layer thickness for the first solution is thinner than that for the second solution. The velocity and thermal boundary-layer thicknesses increase in the first solution, while they decrease with the increase of $\lambda$ in the second solution. Moreover, the velocity and thermal boundary-layer thicknesses decrease in the first solution, while they increase with the increase of $M$ in the second solution. The kerosene-based ferrofluids also have higher skin friction and Nusselt number than water-based ferrofluids for both solutions. Between these two solutions, it is noticed that the first solution is stable and physically realizable, while the second solutions are unstable and not physically realizable.

\section{Nomenclature}

a Constant first-order surface slip parameter

$b \quad$ Constant second-order surface slip parameter

$B_{0} \quad$ Strength of the applied magnetic field

$B(x) \quad$ Magnetic field

$C_{f} \quad$ Skin friction coefficient

$C_{p} \quad$ Specific heat at a constant temperature 


\begin{tabular}{|c|c|}
\hline$f(\eta)$ & Dimensionless stream function \\
\hline$F(\eta)$ & Small relative to stream function \\
\hline$G(\eta)$ & Small relative to temperature function \\
\hline$k_{f}$ & Thermal conductivity of the fluid \\
\hline$k_{s}$ & Thermal conductivity of the solid \\
\hline$k_{n f}$ & Thermal conductivity of the nanofluid \\
\hline$L$ & Characteristic length of the sheet \\
\hline$M$ & Magnetic parameter \\
\hline $\mathrm{Nu}_{x}$ & Local Nusselt number \\
\hline $\operatorname{Pr}$ & Prandtl number \\
\hline$q_{w}$ & Surface heat flux \\
\hline $\operatorname{Re}_{x}$ & Local Reynolds number \\
\hline$S$ & Mass transfer parameter \\
\hline$S_{s i}$ & $\begin{array}{l}\text { Singularities of the mass transfer } \\
\text { parameter }\end{array}$ \\
\hline$t$ & Time \\
\hline$T$ & Nanofluid temperature \\
\hline$T_{\infty}$ & Temperature of the ambient fluid \\
\hline$T_{w}$ & Temperature of the plate \\
\hline$u, v$ & $\begin{array}{l}\text { Velocity components along } x-\text { and } y- \\
\text { axes }\end{array}$ \\
\hline$u_{w}$ & Surface velocity \\
\hline$u_{\text {slip }}$ & Surface slip velocity \\
\hline$U_{\infty}$ & Free stream velocity \\
\hline$v_{w}$ & Mass flux velocity \\
\hline$v_{0}$ & Mass transfer velocity \\
\hline$x, y$ & Cartesian coordinates \\
\hline$\alpha_{f}$ & Thermal diffusivity of the fluid \\
\hline$\alpha_{n f}$ & Thermal diffusivity of the nanofluid \\
\hline$\gamma$ & First-order surface velocity slip \\
\hline$\zeta$ & Unknown eigenvalue parameter \\
\hline$\eta$ & Independent similarity variable \\
\hline$\theta(\eta)$ & Dimensionless temperature function \\
\hline$\lambda$ & Constant moving parameter \\
\hline$\lambda_{s i}$ & $\begin{array}{l}\text { Singularities of the constant moving } \\
\text { parameter }\end{array}$ \\
\hline$\mu_{f}$ & Dynamic viscosity of the fluid \\
\hline$\mu_{s}$ & Dynamic viscosity of the solid \\
\hline$\mu_{n f}$ & Dynamic viscosity of the nanofluid \\
\hline$\nu_{f}$ & Kinematic viscosity of the fluid \\
\hline$\nu_{n f}$ & Kinematic viscosity of the nanofluid \\
\hline$\rho_{f}$ & Density of the fluid \\
\hline$\rho_{s}$ & Density of the solid \\
\hline$\rho_{n f}$ & Density of the nanofluid \\
\hline$\left(\rho C_{p}\right)_{f}$ & Heat capacity of the fluid \\
\hline$\left(\rho C_{p}\right)_{s}$ & Heat capacity of the solid \\
\hline
\end{tabular}

$\begin{array}{ll}\left(\rho C_{p}\right)_{n f} & \text { Heat capacity of the nanofluid } \\ \sigma & \text { Moving parameter } \\ \tau & \text { Dimensionless time variable } \\ \tau_{w} & \text { Skin friction along the plate } \\ \varphi & \text { Volume fraction of solid particle of the } \\ \psi & \text { nanofluid } \\ \omega & \text { Stream function } \\ & \text { Second-order surface velocity slip }\end{array}$

\section{References}

1. Choi, S.U.S. "Enhancing thermal conductivity of fluids with nanoparticles", Dev. Appl. Non-Newtonian Flows, 231, pp. 99-105 (1995).

2. Xuan, Y. and Li, Q. "Heat transfer enhancement of nanofluids", Int. J. Heat Fluid Flow, 21, pp. 58-64 (2000).

3. Tiwari, R. and Das, M. "Heat transfer augmentation in a two-sided lid-driven differentially heated square cavity utilizing nanofluids", Int. J. Heat Mass Transfer, 50, pp. 2002-2018 (2007).

4. Ahmad, S., Rohni, A., and Pop, I. "Blasius and Sakiadis problems in nanofluids", Acta Mech, 218, pp. 195-204 (2011).

5. Tangthieng, C., Finlayson, B., Maulbetsch, J., and Cader, T. "Heat transfer enhancement in ferrofluids subjected to steady magnetic fields", J. Magn. Magn. Mater, 201, pp. 252-255 (1999).

6. Kuncser, V., Schinteie, G., Sahoo, B., Keune, W., Bica, D., Vekas, L., and Filoti, G. "Magnetic interactions in water based ferrofluids studied by Mössbauer spectroscopy", J. Phys.: Condens. Matter, 19(1), pp. 016205-016221 (2007).

7. Li, M., Shi, H., and Zhu, L. "Boundary layer velocity distribution of two special ferromagnetic fluid", Proc. Eng., 31, pp. 166-169 (2012).

8. Khan, W.A., Khan, Z.H., and Haq, R.U. "Flow and heat transfer of ferrofluids over a flat plate with uniform heat flux", Eur. Phys. J. Plus, 130(86), 10 pages (2015).

9. Sheremet, M.A., Pop, I., and Roşca, N.C. "Magnetic field effect on the unsteady natural convection in a wavy-walled cavity filled with a nanofluid: Buongiorno's mathematical model", J. Taiwan Institute Chemical Engineers, 61, pp. 211-222 (2016).

10. Bondareva, N.S., Sheremet, M.A., and Pop, I. "Magnetic field effect on the unsteady natural convection in a right-angle trapezoidal cavity filled with a nanofluid: Buongiorno's mathematical model", Int. J. Numerical Methods Heat Fluid Flow, 25, pp. 1924-1946 (2015).

11. Roşca, A.V. and Pop, I. "Flow and heat transfer over a vertical permeable stretching/shrinking sheet with a second order slip", Int. J. Heat Mass Transfer, 60, pp. 355-364 (2013). 
12. Weidman, P.D., Kubitschek, D.G., and Davis, A.M.J. "The effect of transpiration on self-similar boundary layer flow over moving surfaces", Int. J. Engng. Sci., 44, pp. 730-737 (2006).

13. Harris, S.D., Ingham, D.B., and Pop, I. "Mixed convection boundary-layer flow near the stagnation point on a vertical surface in a porous medium: Brinkman model with slip", Transport Porous Media, 77, pp. 267-285 (2009).

14. Cortell, R. "Numerical solutions of the classical Blasius flat-plate problem", Appl. Math. Comput., 170, pp. 706-710 (2005).

15. Yazdi, M., Abdullah, S., Hashim, I., and Sopian, K. "Effects of viscous dissipation on the slip MHD flow and heat transfer past a permeable surface with convective boundary conditions", Energies, 4, pp. 2273-2294 (2011).

\section{Biographies}

Norshafira Ramli is a PhD Candidate in the School of Mathematical Sciences at Universiti Sains Malaysia, Malaysia. She received her BSc degree in Mathematics from University of Birmingham, United Kingdom and also her MSc degree in Mathematics from Universiti Sains Malaysia, Malaysia, in 2011 and 2012, respectively. Her research interests are numerical analysis and fluid mechanics.

Syakila Ahmad received a $\mathrm{PhD}$ degree in Fluid Dynamics from Universiti Putra Malaysia, Malaysia. She is now a Senior Lecturer at School of Mathematical Sciences, Universiti Sains Malaysia, Malaysia. Her research interests are applied mathematics: fluid dynamics, convective boundary-layer flow and heat transfer, and mathematical modelling.

Ioan Pop is a Professor of Applied Mathematics in the Faculty of Mathematics and Computer Science, Babeş-Bolyai University, Cluj-Napoca, Romania. He received his $\mathrm{PhD}$ degree from University of Bucharest, Romania in 1970. His research interests are applied mathematics: fluid mechanics and heat transfer with application to the boundary-layer theory, heat transfer in Newtonian and non-Newtonian fluids, and magnetohydrodynamics and convective flow in fluid-saturated porous media. 